\title{
Histopathological changes in malignant melanomas of the choroid after cobalt plaque therapy
}

\author{
P. A. MAcFAUL AND G. MORGAN \\ From the Oncology Clinic, Moorfields Eye Hospital, London, EC1, and the Department of Pathology, \\ Institute of Ophthalmology, Judd Street, London, WC1
}

SUMMARY A series of 23 eyes removed after cobalt plaque therapy for malignant melanoma of the choroid is presented, and the histological changes are described with particular reference to the presence or absence of necrosis in the tumours. In 17 of the 23 eyes no evidence of tumour necrosis was found, though all showed evidence of radiation changes in the adjacent tissues. Necrosis was found in 6 cases but was prominent in only 2, one of which was the only example of a mixed-cell tumour, the other 22 being spindle-cell tumours. Enucleation became necessary on average at about 32 months after treatment ( 23 out of 100 treated eyes) because of obvious failure of treatment with evidence of continued growth, or because of radiational complications leading to a painful blind eye. The 5-year survival rate was $86 \%$ compared with about $50 \%$ when the treatment is enucleation.

From 1960 to 1975 in the Oncology Clinic at Moorfields Eye Hospital 420 patients were seen with malignant melanoma of the choroid of which 300 were treated by primary enucleation and 100 by the application of a cobalt plaque. Others were treated by light coagulation, and in some cases, particularly in older people, no active treatment was given but the patient was kept under careful observation.

The purpose of this paper is to report 23 cases in which the eyes have been removed after cobalt plaque therapy for malignant melanoma of the choroid and to describe the histopathological changes.

\section{Case reports}

The ages of the patients varied between 30 and 75 years (average 51 years), and there were 14 males and 9 females. The interval between treatment by cobalt plaque therapy and enucleation of the affected eye varied from 7 months to 13 years and 10 months, but when the latter case is excluded the average interval was 32 months. The reasons for enucleation fell into 2 groups-failure of treatment with strong suspicion or clear clinical evidence of continued growth of the tumour, and radiation complications in the treated eye.

Address for reprints: Mr P. A. MacFaul, Institute of Ophthalmology, Judd Street, London WC1H 9QS

\section{CASE 1}

Female aged 47, presented in January 1962 with a malignant melanoma of the choroid affecting the infero-temporal quadrant of the left eye near the optic disc. A $10 \mathrm{~mm}$ cobalt plaque was applied, but the eye became blind and was enucleated 15 months after treatment. The patient is alive without recurrence 14 years after cobalt therapy.

Microscopical examination of the eye showed a spindle cell malignant melanoma of the choroid, with a moderate pigment content and a light reticulin content. There was no evidence of extraocular extension. A small area of necrosis was seen in the base of the neoplasm.

There was proliferation of the choroidal pigment adjacent to the growth, atrophy of Bruch's membrane and of the pigment epithelium over the tumour, subretinal exudate, and exudates in the detached retina overlying the melanoma.

\section{CASE 2}

This 59-year-old man had a large tumour at the posterior pole of his right eye treated by a $10 \mathrm{~mm}$ cobalt plaque. The eye was enucleated 10 months after treatment because of increasing size of the tumour. The patient is alive without recurrence 11 years after cobalt therapy.

Microscopical examination of the eye showed a spindle cell malignant melanoma of the choroid, having a moderate pigment and reticulin content. 
There was no evidence of necrosis, and extraocular extension was not seen.

There was thickening and narrowing of the posterior ciliary arteries, but the other structures were histologically normal in appearance.

\section{CASE 3}

Female aged 55, presented in 1963 with a history of blurred vision in the left eye for 3 months. A choroidal neoplasm was found in this eye, with a visual acuity of $6 / 12$. A $15 \mathrm{~mm}$ cobalt plaque was applied, but postoperatively the mass increased in size and a retinal detachment developed. The eye was removed $2 \frac{1}{2}$ years after treatment and the patient died 5 years later, having survived 6 years after cobalt therapy. There was no recurrence of the tumour but the cause of death is unknown.

Microscopical examination of the eye showed a spindle cell malignant melanoma of the choroid with a moderate pigment and reticulin content. There was no evidence of necrosis, and extraocular extension was not seen. The tumour was infiltrated by a moderate number of lymphocytes.

There was detachment of the retina, with albuminous exudate in the subretinal space.

\section{CASE 4}

Female aged 66. In 1961 an infero-temporal mass was discovered in the left eye, which was kept under observation until 1965, when the vision suddenly decreased owing to secondary retinal detachment. By this time the mass was considered too large for conservative therapy, but enucleation was refused by the patient, and she was treated by light coagulation and the application of a $15 \mathrm{~mm}$ cobalt plaque. Four months after treatment vision was almost completely lost owing to a dense vitreous haemorrhage which slowly cleared, but in July 1966, 9 months after treatment, clinical examination showed active tumour and the eye was removed. She is alive without recurrence 11 years after cobalt therapy.

Microscopical examination of the eye showed a spindle cell malignant melanoma of the choroid, having a moderate pigment content and a light reticulin content. Small areas of necrosis were seen peripherally and at the apex. There was no evidence of extraocular extension.

There was pigment proliferation and atrophy of the adjacent choroid. Bruch's membrane and the pigment epithelium overlying the tumour showed atrophic changes, and the overlying retina showed an area of necrosis with pigment migration.

CASE 5

This 54-year-old man had a malignant melanoma of the choroid treated by cobalt plaque therapy in 1962. Five years later there was a large active tumour at the posterior pole and the eye was removed. $\mathrm{He}$ is alive without recurrence 14 years after cobalt therapy.

Microscopical examination of the eye showed a lightly pigmented, spindle cell malignant melanoma of the choroid, with a moderate reticulin content. Haemorrhages were present within the tumour, but there was no evidence of necrosis nor extraocular extension.

There was atrophy of Bruch's membrane and of the pigment epithelium overlying the tumour, and with detachment and atrophy of the retina in that region; haemorrhagic exudate was present in the subretinal space.

\section{CASE 6}

Female aged 38, presented with a choroidal malignant melanoma anterior to the equator in the upper temporal quadrant and under the lateral rectus. Two cobalt plaques (15 and $10 \mathrm{~mm}$ in diameter) were applied and light coagulation was also used. Three years after treatment the eye was removed because of severe necrosis of the sclera with threatened perforation of the globe. The patient is alive without recurrence 8 years after cobalt therapy.

Microscopical examination of the eye showed a lightly pigmented, spindle cell malignant melanoma of the choroid with a light reticulin content. There was no evidence of necrosis, and extraocular extension was not seen.

There was atrophy of the choroid and sclera adjacent to the tumour, and exudates and atrophic changes were seen in the retina overlying the neoplasm. There was atrophy of Bruch's membrane and of the overlying pigment epithelium.

\section{CASE 7}

Male aged 50. A choroidal malignant melanoma was discovered in the infero-nasal quadrant between the equator and optic disc of the left eye. Treatment was by a $10 \mathrm{~mm}$ cobalt plaque. Postoperatively the mass remained unchanged in size; the eye became blind with intraocular haemorrhage and secondary glaucoma, and was removed 14 months after treatment. The patient died from bronchopneumonia 4 years after cobalt therapy. There was no evidence of recurrence of the tumour.

Microscopical examination of the eye showed a lightly pigmented, spindle cell malignant melanoma with a light reticulin content. A small area of necrosis was seen at the apex of the tumour, which also showed haemorrhages. There was no evidence of extraocular extension.

There was atrophy of Bruch's membrane and of 
the pigment epithelium overlying the tumour, and haemorrhage was present in the vitreous.

CASE 8

Male aged 55, presented with a malignant melanoma of the choroid in the infero-temporal quadrant of the right eye near the optic disc. He was treated with a $7.5 \mathrm{~mm}$ cobalt plaque; 14 months later the mass was clearly increasing in size, and the tumour was considered to be active. The eye was removed. The patient is alive without recurrence 7 years after cobalt therapy.

Microscopical examination of the eye showed a lightly pigmented, spindle cell malignant melanoma of the choroid, having a heavy reticulin content. There was no evidence of necrosis, and extraocular extension was not seen.

There were atrophic changes in the adjacent choroid, atrophic changes in the detached retina overlying the tumour, and exudate in the subretinal space.

CASE 9

Female aged 65 , presented with a large choroidal tumour in the infero-nasal quadrant of her left eye near the optic disc. A $15 \mathrm{~mm}$ cobalt plaque was applied, and 15 months later a clinically active melanoma was evident, with increasing serous retinal detachment. The eye was removed 18 months after treatment. She is alive without recurrence 7 years after cobalt therapy.

Microscopical examination of the eye showed a lightly pigmented, spindle cell malignant melanoma of the choroid with a light reticulin content. There was no evidence of necrosis, and extraocular extension was not seen.

There was marked atrophy of the adjacent choroid, atrophy of the overlying Bruch's membrane and of the pigment epithelium, and exudates and atrophic changes in the overlying retina.

\section{CASE 10}

Male aged 54, presented in August 1967 with a large malignant melanoma of the choroid in the infero-temporal quadrant of his left eye, extending towards the macula. The right eye was normal. The tumour was considered to be too large for conservative therapy, but the patient refused enucleation and was therefore treated with a $15 \mathrm{~mm}$ cobalt plaque. He retained some vision in this eye until August 1969, when a massive choroidal and subretinal haemorrhage occurred, leading to secondary glaucoma and complete loss of vision. The eye was removed 2 years after treatment, at which time he also had massive liver metastases. He died 4 years after cobalt therapy.
Microscopical examination of the eye showed a mixed-cell malignant melanoma of the choroid, having a moderate content of pigment and reticulin. There was extensive haemorrhagic necrosis of the tumour, which showed infiltration by lymphocytes.

There was atrophy, haemorrhages, and pigment proliferation of the adjacent choroid, atrophy of the overlying Bruch's membrane and of the retinal pigment epithelium, and diffuse atrophy of the adjacent detached retina. The subretinal space contained haemorrhagic exudate.

CASE 11

Male aged 60. This patient was first seen in April 1967 with a large malignant melanoma of the choroid in the infero-nasal quadrant of his left eye extending up to the optic disc. Vision in this eye was $6 / 6$ but in the right eye vision was reduced to $6 / 60$ as a result of concussional damage to the retina following an injury by a tennis ball at the age of 24 . The left eye was his only useful eye, therefore, and was treated by means of a $10 \mathrm{~mm}$ cobalt plaque with an overlapping C-shaped plaque. In April 1968 the vision was $6 / 18$ and the mass was smaller but still active. In January 1969, 20 months after treatment, he presented with complete loss of vision in the treated eye owing to ischaemia of the optic nerve and retinal artery. The eye was removed in December 1969, 29 months after treatment. The patient died in March 1970 from endocarditis and septicaemia, 3 years after cobalt therapy. There was no evidence of tumour recurrence.

Microscopical examination of the eye showed a lightly pigmented, spindle cell malignant melanoma of the choroid, with a light reticulin content. There was no evidence of necrosis, and extraocular extension was not seen.

The adjacent choroid showed sclerotic narrowing of its vessels, with atrophy and pigment proliferation. Atrophic changes were seen in the overlying Bruch's membrane and the pigment epithelium, and exudates and atrophic changes were seen in the overlying retina. The vitreous contained haemorrhages. There was thickening and narrowing of the posterior ciliary arteries.

\section{CASE 12}

Male aged 56. This patient was first seen by his optician in 1965, who found a pigmented lesion in the left fundus which was thought to be an area of inactive choroiditis. In October 1969 he complained of blurred vision in his left eye of 3 weeks' duration. Vision was $6 / 9$ and in the lower temporal quadrant there was a protuberant collar-stud choroidal melanoma with a small associated secondary retinal detachment. The right eye was normal. It was 
thought that the height of the lesion in his left eye precluded conservative therapy, but as the vision was still good a $10 \mathrm{~mm}$ cobalt plaque was applied. Subsequently the mass appeared to regress slightly, but the secondary retinal detachment extended, vision deteriorated, and the eye was removed 18 months after treatment, by which time it was completely blind and divergent with a total retinal detachment, rubeosis, and cataract. $\mathrm{He}$ is alive without recurrence 7 years after cobalt therapy.

Microscopical examination of the eye showed a lightly pigmented, predominantly spindle cell malignant melanoma of the choroid, with a heavy reticulin content. There were small areas of necrosis at the base on either side and near the apex. There was no evidence of extraocular extension.

The adjacent choroid showed sclerosed vessels, pigment proliferation, and atrophy. There were atrophic changes of Bruch's membrane and the pigment epithelium overlying the tumour, and the detached retina showed exudates and haemorrhages. The subretinal space contained albuminous exudate.

\section{CASE 13}

Male aged 53, presented in October 1966 with a history of flashing lights in his left eye for 6 months and loss of the lower field of vision 4 weeks previously. The right eye was normal with vision $6 / 6$. Vision in the left eye was reduced to counting fingers and there was a massive tumour in the temporal half of the fundus with extensive serous retinal detachment. He refused enucleation and was treated with a $10 \mathrm{~mm}$ cobalt plaque in November 1966. Four months later the detachment had disappeared and it was thought that the tumour was smaller. At this time he showed epilation of the eyebrow hair on the side where the plaque had been placed and by August 1967, 9 months after treatment, he had an established radiation keratopathy with a typical dry-eye syndrome due to decreased tear secretion. Vision was down to $6 / 60$ and further regression of the tumour was noted. In February 1971 vision was reduced to counting fingers with extensive intraocular haemorrhage, and by December 1971 the eye was blind and painful with intraocular haemorrhage, gross rubeosis, dense cataract, and increased intraocular pressure. In March 1972, because of severe pain, the eye was removed. He is alive without recurrence 10 years after cobalt therapy.

Microscopical examination of the eye showed a lightly pigmented, spindle cell malignant melanoma of the choroid with a light reticulin content. Haemorrhages were seen in the tumour, but there was no evidence of necrosis or of extraocular extension.

There were haemorrhages and pigment proliferation in the adjacent choroid, atrophy of the over- lying Bruch's membrane and pigment epithelium, and detachment of the overlying retina, which showed thickened, narrowed vessels, exudates, haemorrhages, atrophic changes, and pigment migration. Subretinal haemorrhagic exudate was present.

\section{CASE 14}

Male aged 50, presented in July 1970 with a 3month history of a gradual onset of distorted vision, micropsia, and more recent blurring of vision. The left eye was normal. Right vision was down to 6/36 and a large melanoma was found adjacent to the posterior pole in this eye. A $10 \mathrm{~mm}$ cobalt plaque was applied, and in June 1971 vision was down to $6 / 60$ and there was a marked radiation keratopathy, but the mass appeared to have regressed to some extent. In September 1971, however, a serous retinal detachment appeared, and the tumour was considered to be still active. The eye was removed in April 1972, 20 months after treatment. The patient is alive without recurrence 6 years after cobalt therapy.

Microscopical examination of the eye showed a lightly pigmented, spindle cell malignant melanoma of the choroid, with a heavy reticulin content. There was no evidence of necrosis, and extraocular extension was not present.

There was atrophy and pigment proliferation of the adjacent choroid, atrophy of the overlying Bruch's membrane and the pigment epithelium, and detachment of the retina, which showed exudates, atrophy, and some pigment migration.

CASE 15

Male aged 44. This man was first seen in November 1968 with a 3-month history of blurred vision in the upper temporal field of his left eye. Examination showed a visual acuity of $6 / 6$ in each eye, and in the left eye a bulky choroidal neoplasm with a small secondary detachment was found on the nasal side of the fundus near the optic disc. It was considered too large and too near the optic disc for cobalt plaque therapy. The patient refused enucleation and insisted on conservative treatment, having been warned that he would certainly lose vision owing to the proximity of the neoplasm to the optic nerve. A $15 \mathrm{~mm}$ cobalt plaque was applied in December 1968 and 3 months later the detachment had cleared completely and the mass was smaller with vision retained at 6/9. By November 1970 vision had deteriorated slightly to $6 / 12$ but had dropped to 6/60 by May 1971. In September 1971 the eye was blind with chronic uveitis, posterior synechiae, and extensive choroido-retinal degeneration. Fluorescein angiography in December 1971 showed that there 


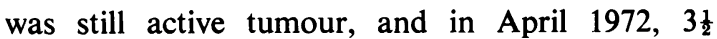
years after treatment, the eye, which by then was painful as well as blind, was removed. He is alive without recurrence 7 years after cobalt therapy.

Microscopical examination of the eye showed a heavily pigmented, spindle cell malignant melanoma of the choroid with a heavy reticulin content. There was extensive necrosis, but no evidence of extraocular extension was seen.

There was atrophy and pigment proliferation of the adjacent choroid, atrophy of the overlying Bruch's membrane and the pigment epithelium, and sclerosed vessels, exudates, necrosis, and atrophy of the overlying retina.

CASE 16

Male aged 49, presented in March 1971 with a 4week history of visual distortion followed by a shadow over the left visual field. Visual acuity was $6 / 5$ in each eye. In the left eye a choroidal melanoma was found in the lower temporal quadrant and a $7.5 \mathrm{~mm}$ cobalt plaque was applied. Five months later vision was down to $6 / 18$, the retinal detachment had disappeared, and the mass was smaller; in March 1972 the detachment recurred and fluorescein angiography suggested that the tumour was still active. The eye was removed 2 months later, 1 year after treatment. The patient is alive without recurrence 5 years after cobalt therapy.

Microscopical examination of the eye showed a lightly pigmented, spindle cell malignant melanoma of the choroid with a light reticulin content. There was no evidence of necrosis, and extraocular extension was not seen.

There was atrophy of the overlying Bruch's membrane and pigment epithelium, haemorrhages and atrophic changes of the detached retina, and haemorrhagic exudate was present in the subretinal space.

\section{CASE 17}

Female aged 40. This patient was first seen in October 1970 with a 2-week history of shimmering vision in the right eye, preceded by floating spots for several months. Right vision was down to 6/24 and there was a solid mass in the postero-equatorial fundus on the temporal side, with a shallow detachment extending towards the macula. A $10 \mathrm{~mm}$ cobalt plaque was applied and 5 months later the mass was showing signs of regression with complete resolution of the detachment. The lesion appeared to have increased in size in August 1972, and fluorescein angiography indicated an active tumour; the right eye was removed in November 1972. She is alive without recurrence 6 years after cobalt therapy. Microscopical examination of the eye showed a heavily pigmented, spindle cell malignant melanoma of the choroid, with a moderate reticulin content. There was no evidence of necrosis and extraocular extension was not seen.

There was atrophy and pigment proliferation of the adjacent choroid, atrophy of the overlying Bruch's membrane and the pigment epithelium, and detachment of the retina, which showed exudates, atrophy and some pigment migration.

\section{CASE 18}

Female aged 37, presented in August 1970 with a 3-month history of distorted vision in the right eye due to a malignant melanoma of the choroid on the temporal side, with a secondary serous detachment reducing vision to $6 / 9$. A $10 \mathrm{~mm}$ cobalt plaque was applied, with improved visual acuity as the detachment disappeared. 18 months later vision had dropped to 6/60 with enlargement of the choroidal mass and recurrence of the detachment. From the clinical signs and fluorescein angiography the tumour was regarded as being still active, and the eye was removed 3 years after treatment. She is alive without recurrence 6 years after cobalt therapy.

Microscopical examination of the eye showed a spindle cell malignant melanoma of the choroid with a marked pigment content and heavy reticulin content. There was no evidence of necrosis, and extraocular extension was not seen. A small number of lymphocytes infiltrated the tumour.

There was atrophy and pigment proliferation of the adjacent choroid and atrophy of the overlying Bruch's membrane and the pigment epithelium. The overlying retina was detached and showed exudates and atrophic changes. The subretinal space contained albuminous exudate.

\section{CASE 19}

Male aged 45. A greyish swelling was found in the lower temporal quadrant of the left eye at a routine sight test which showed normal vision. In August 1963 a $10 \mathrm{~mm}$ cobalt plaque was applied, and the tumour regressed. Three years later vision was $6 / 18$ and the lesion appeared inert. In January 1970 vision dropped suddenly owing to a vitreous haemorrhage, and when this cleared numerous retinal haemorrhages and vascular changes were seen near the irradiated area. In February 1972 vision was down to $6 / 60$; the lesion appeared elevated again and fluorescein angiography suggested that the tumour was active. 12 months later vision had dropped to hand movements only, and shortly afterwards glaucoma developed owing to irreversible vascular complications; the eye was removed. He is alive without recurrence 13 years after cobalt therapy. 
Microscopical examination of the eye showed a lightly pigmented, spindle cell malignant melanoma of the choroid with a light reticulin content. There was no evidence of necrosis, and extraocular extension was not seen. Haemorrhage was present within the tumour.

There was atrophy and pigment proliferation of the adjacent choroid, atrophy of the overlying Bruch's membrane and pigment epithelium, and diffuse necrosis of the overlying detached and haemorrhagic retina. Haemorrhage was seen in the subretinal space and vitreous.

CASE 20

Male aged 36, presented in May 1969 with floating spots in the right eye for 3 months and a choroidal swelling which was discovered by his optician. The vision was $6 / 6$ an $\downarrow$ a malignant melanoma with a small serous detachment was present on the nasal side of the fundus. This was treated by a $15 \mathrm{~mm}$ cobalt plaque. 12 months later the vision was $6 / 6$ and the tumour appeared inert. Two years later the vision had decreased to $6 / 18$ over a few months and numerous retinal haemorrhages were present. In September 1972 there was a large haemorrhage at the macula, and in December 1973 a massive vitrous haemorrhage occurred, reducing vision to light perception only. Two months later the eye was virtually blind, with dense vitreous haemorrhage preventing any view of the fundus. The eye was removed. The patient is alive without recurrence 7 years after cobalt therapy.

Microscopical examination of the eye showed a spindle cell malignant melanoma of the choroid, having a moderate pigment and reticulin content. There was no evidence of necrosis, and extraocular extension was not seen.

There was a normal choroid, and some atrophy of the overlying Bruch's membrane, pigment epithelium, and retina. Some haemorrhage was present in the vitrous.

\section{CASE 21}

Male aged 30. This patient noticed blurred vision in his left eye for 3 months, which was due to a malignant melanoma on the temporal side with an extensive inferior retinal detachment. A $10 \mathrm{~mm}$ cobalt plaque was applied in April 1969, and the detachment rapidly regressed. In June 1971 the vision was $6 / 9$ and the mass appeared inert, although still slightly elevated. 12 months later the vision had dropped to $6 / 18$ with a recurrence of the serous retinal detachment, and fluorescein angiography suggested that the tumour was active. In February 1974 the detachment had extended, with reduction of vision to $6 / 60$, and the eye was removed $4 \frac{1}{2}$ years after treatment. He is alive without recurrence 7 years after cobalt therapy.

Microscopical examination of the eye showed a lightly pigmented, spindle cell malignant melanoma of the choroid with a moderate reticulin content. There was no evidence of necrosis or of extraocular extension.

There was pigment proliferation of the adjacent choroid and atrophy of the overlying Bruch's membrane and pigment epithelium. The overlying detached retina showed atrophy and small haemorrhages, and the subretinal space contained haemorrhagic exudate.

\section{CASE 22}

This 75-year-old woman had a malignant melanoma of the choroid in her left eye, which was kept under observation for 2 years before the application of a cobalt plaque; this was followed by some episcleral necrosis and failure of the tumour to respond. The eye was enucleated 7 months after the application of the plaque, and she is alive without recurrence 1 year after cobalt therapy.

Microscopical examination of the eye showed a spindle cell malignant melanoma of the ciliary body and choroid with a moderate content of pigment and reticulin. There was no evidence of necrosis or of extraocular extension.

There was some superficial episcleral necrosis overlying the tumour. The adjacent choroid showed atrophic changes and pigment proliferation, and atrophic changes were also present in the overlying Bruch's membrane, pigment epithelium, and retina.

\section{CASE 23}

Female aged 50. A malignant melanoma of the choroid was treated with a cobalt plaque in 1961 and light coagulation in 1962, after which the vision was reduced to hand movements. A prominent swelling remained but without clinical signs of activity until March 1975, when a large vitreous haemorrhage occurred with loss of light perception; the eye was removed. She is alive without recurrence 15 years after cobalt therapy.

Microscopical examination of the eye showed a lightly pigmented, spindle cell malignant melanoma of the choroid with a heavy reticulin content. There was no evidence of extraocular extension or of necrosis, but extensive haemorrhage was seen within the tumour.

There was extensive atrophy of the adjacent choroid and extensive atrophy of the overlying Bruch's membrane, pigment epithelium, and detached retina. Extensive haemorrhage was present in the vitreous and subretinal space. 
A summary of the pathological findings is shown in Tables 1 and 2 and of the survival rate in Table 3.

Table 1 Summary of pathological findings in 23 cases of malignant melanoma of choroid

\begin{tabular}{|c|c|c|}
\hline $\begin{array}{l}\text { Cell type } \\
\text { (a) Spindle } \\
\text { (b) Epithelioid } \\
\text { (c) Mixed }\end{array}$ & $\begin{array}{r}22 \\
0 \\
1\end{array}$ & $\begin{array}{l}\text { (Cases 1-9, 11-23) } \\
\text { (Case 10) }\end{array}$ \\
\hline $\begin{array}{l}\text { Pigment content } \\
\text { (a) Light } \\
\text { (b) Moderate } \\
\text { (c) Heavy }\end{array}$ & $\begin{array}{r}13 \\
7 \\
3\end{array}$ & $\begin{array}{l}(\text { Cases } 5-9,11-14,16,19,21,23) \\
(\text { Cases } 1-4,10,20,22) \\
(\text { Cases } 15,17,18)\end{array}$ \\
\hline $\begin{array}{l}\text { Reticulin content } \\
\text { (a) Light } \\
\text { (b) Moderate } \\
\text { (c) Heavy }\end{array}$ & $\begin{array}{l}9 \\
8 \\
6\end{array}$ & $\begin{array}{l}(\text { Cases } 1,4,6,7,9,11,13,16,19) \\
(\text { Cases } 2,3,5,10,17,20-22) \\
(\text { Cases 8, 12, 14, 15, 18, 23) }\end{array}$ \\
\hline $\begin{array}{l}\text { Necrosis } \\
\text { (a) More than } 50 \% \text { of } \\
\text { tumour } \\
\text { (b) Less than } 50 \% \text { of } \\
\text { tumour } \\
\text { (c) None }\end{array}$ & $\begin{array}{r}2 \\
4 \\
17\end{array}$ & $\begin{array}{l}\text { (Cases 10, 15) } \\
(\text { Cases 1, 4, 7, 12) } \\
(\text { Cases } 2,3,5,6,8,9,11,13,14,16 \text {, } \\
\quad 17,18,19,20,21,22,23)\end{array}$ \\
\hline Haemorrhages & 6 & (Cases $5,7,10,13,19,23)$ \\
\hline Lymphocytic infiltration & 3 & (Cases 3, 10, 18) \\
\hline
\end{tabular}

Table 2 Summary of pathological findings: remaining ocular structures

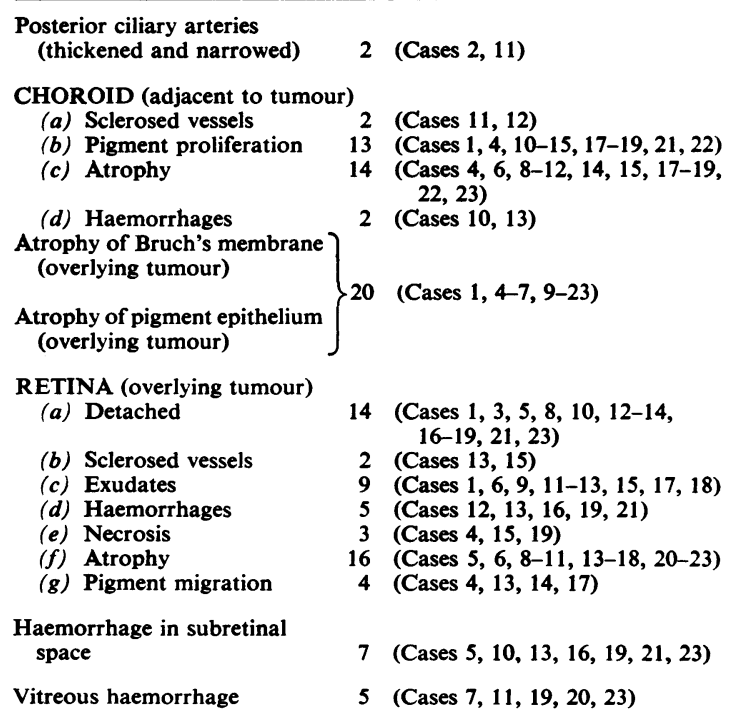

Table 3 Survival rate

\begin{tabular}{llll}
\hline $\begin{array}{l}\text { Number of } \\
\text { patients }\end{array}$ & Dead & $\begin{array}{l}\text { Five-year } \\
\text { survival rate }\end{array}$ \\
\cline { 2 - 4 } & From tumour & Other causes & $86 \%$ \\
\hline 23 & 1 & 3 & $86 \%$ \\
\hline
\end{tabular}

\section{Discussion}

For many years the usual treatment of cases of choroidal malignant melanoma has been enucleation of the affected eye. Generally the decision for enucleation presents no difficulty and is accepted by the patient. In some cases, however, because of its position and size when discovered, the tumour may not seriously impair vision or may be found in what is, for practical purposes, the patient's only eye; in these circumstances the patient may refuse enucleation. Furthermore, the advantage of enucleation in terms of increased life expectancy is not firmly established. Many attempts have been made, therefore, to develop methods of conservative treatment for this type of malignant disease, whereby the tumour may be destroyed and some useful vision preserved in the treated eye.

The methods adopted have included destruction of the neoplasm by diathermy (Weve, 1935; Goldsmith, 1943; Melchers, 1953; Boniuk and Girard, 1965; Davidorf et al., 1970); ionising radiation using radon seeds (Moore et al., 1931; Newman et al., 1970), radium discs (Stallard, 1952), cobalt-60 gamma-ray applicators (Stallard, 1959, 1968; Bedford, 1968; Long et al., 1971), and ruthenium-106 beta-ray applicators (Lommatzsch, 1973); light coagulation (Meyer-Schwickerath, 1961; Lund, 1962, 1966; Curtin and Norton, 1963; Makley et al., 1965; Hepler et al., 1968; Francois, 1965, 1968a and b; Dufour et al., 1968; Vogel, 1972, 1973), and cryotherapy (Lincoff et al., 1967; Campinchi, 1968; Davidorf et al., 1970). Others have attempted to save the eye by surgical techniques as by choroidectomy (Stallard, 1973). In recent years there has developed a policy of no active intervention but careful observation of patients with initially small asymptomatic melanomata and good vision, particularly in the elderly, provided there is no evidence of extension or involvement of other intraocular structures (Curtin and Cavender, 1974; Zimmerman and McLean, 1975).

That cobalt plaque therapy is highly effective in cases of retinoblastoma is not in doubt (Bedford et al., 1971), but in cases of malignant melanoma of the choroid the success rate is less and the complication rate high, particularly loss of vision due to retinal vascular occlusion and optic nerve ischaemia (MacFaul and Bedford, 1970; Bedford et al., 1970). Furthermore, it is now clear that some tumours do not respond at all to cobalt plaque therapy. After a period of apparent regression the neoplasm shows signs of continued growth with recurrence of serous retinal detachment, with increase in size, or with intraocular haemorrhage; the eye must then be removed. On the other hand enucleation may 
become necessary because of radiational complications leading to a painful blind eye even though the neoplasm appears clinically to have been destroyed. In cases which do respond with regression to a more or less flat scar there are after many months distinctive and progressive vascular changes in the fundus around the base of the tumour, which may take up to 2 years or more to mature, and it is now thought that in those successful cases regression is caused by progressive radiation-induced ischaemia rather than by the direct cytotoxic effect of radiation on the tumour (Bedford, 1973).

Enucleation became necessary in 23 of our 100 cases treated by cobalt plaque therapy at Moorfields Eye Hospital, and histological examination of these eyes has shown that in 17 eyes there was no evidence of necrosis in the tumour, although there was clear evidence of radiation-induced changes in the adjacent tissues. In 6 eyes, signs of necrosis were found, but the extent of necrosis could not be correlated with cell type, pigment content, or reticulin content. However, the one example of a mixed cell melanoma did show extensive necrosis, whereas 17 out of the 22 spindle cell tumours showed no necrosis. Of the 2 cases showing extensive necrosis lymphocytic infiltration was found in 1 case (case 10), suggesting an immunological response; in the other 2 cases with similar infiltration necrosis was not evident.

The expression of the overall prognosis in percentages following enucleation for malignant melanoma is difficult. In general, however, the 5year survival rate is about $50 \%$ (Duke-Elder and Perkins, 1966). In our series the 5-year survival rate following cobalt therapy was $86 \%$.

In a future report of the results of treatment for malignant melanoma of the choroid it is proposed to consider the possible reasons for failure of treatment in these cases in detail, but it is relevant here to note that several of the cases were deemed unsuitable for conservative treatment in view of the size and position of the tumour, but cobalt plaque therapy was applied in most of them because the patient refused to accept enucleation.

We are grateful to $\mathrm{Mr} \mathrm{M}$. A. Bedford for his interest and permission to report on cases under his care and to Professor N. Ashton for his interest and advice. We thank Mr V. J. Elwood for technical assistance and Miss E. M. FitzGerald and Mrs A. Wood for secretarial help.

\section{References}

Bedford, M. A. (1968). Proceedings of the Royal Society of Medicine, 6, 1041.
Bedford, M. A. (1973). Transactions of the Ophthalmological Society of the United Kingdom, 93, 139.

Bedford, M. A., Bedotto, C., and MacFaul, P. A. (1970). British Journal of Ophthalmology, 54, 505.

Boniuk, M., and Girard, L. J. (1965). American Journal of Ophthalmology, 59, 212.

Campinchi, R. (1968). Archives d'Ophthalmologie, 28, 869.

Curtin, V. T., and Cavender, J. C. (1974). Modern Problems in Ophthalmology, 12, 523.

Curtin, V. T., and Norton, E. W. D. (1963). Archives of Ophthalmology, 69, 744.

Davidorf, F. H. et al. (1970). Archives of Ophthalmology, 83, 273.

Dufour, R., et al. (1968). Modern Problems in Ophthalmology, 7, 39.

Duke-Elder, S., and Perkins, E. S. (1966). System of Ophthalmology, Vol. 9, p. 909. London, Kimpton.

Francois, J. (1965). Transactions of the Ophthalmological Society of the United Kingdom, 85, 179.

Francois, J. (1968a). Modern Problems in Ophthalmology, $7,8$.

Francois, J. (1968b). American Journal of Ophthalmology, 66, 443 .

Goldsmith, A. J. B. G. (1943). Transactions of the Ophthalmological Society of the United Kingdom, 63, 88.

Hepler, R. S., Allen, R. A., and Straatsma, B. R. (1968). Archives of Ophthalmology, 79, 177.

Lincoff, H., McLean, J., and Long, R. (1967). American Journal of Ophthalmology, 63, 389.

Lommatzsch, P. K. (1973). Transactions of the Ophthalmological Society of the United Kingdom, 93, 119.

Long, R. S., Galin, M. A., and Rotman, M. (1971). Transactions of the American Academy of Ophthalmology and Otolaryngology, 75, 84.

Lund, O. E. (1962). Albrecht von Graefes Archiv für Klinische und Experimentalle Ophthalmologie, 164, 433.

Lund, O. E. (1966). Archives of Ophthalmology, 75, 458.

MacFaul, P. A., and Bedford, M. A. (1970). British Journal of Ophthalmology, 54, 237.

Makley, T. A., Havener, W. H., and Newberg, J. (1965). American Journal of Ophthalmology, 60, 1082.

Melchers, M. J. (1953). Diathermy Treatment of IntraOcular Tumours. Thesis, Utrecht University.

Meyer-Schwickerath, G. (1961). Archives of Ophthalmology, 66, 458 .

Moore, R. F., Stallaid, H. B., and Milner, J. G. (1931). British Journal of Ophthalmology, 15, 673.

Newman, G. H., et al. (1970). Archives of Ophthalmology, 83, 21 .

Stallard, H. B. (1952). Transactions of the Ophthalmological Society of the United Kingdom, 72, 417.

Stallard, H. B. (1959). Transactions of the Ophthalmological Society of the United Kingdom, 79, 373.

Stallard, H. B. (1968). Modern Problems in Ophthalmology, $7,16$.

Stallard, H. B. (1973). Transactions of the Ophthalmological Society of the United Kingdom, 93, 69.

Vogel, M. (1972). American Journal of Ophthalmology, 74, $1,466$.

Vogel, M. (1973). Transactions of the Ophthalmological Society of the United Kingdom, 93, 133.

Weve, H. (1935). Nederlandsch Tijdschrift voor Geneeskunde, 79, 754.

Zimmerman, L. E., and McLean, I. W. (1975). Transactions of the Ofhthalmological Society of the United Kingdom, 95, 487. 